\title{
Review
}

\section{BRCA1 and BRCA2 proteins: roles in health and disease}

\author{
J A Duncan, J R Reeves, T G Cooke
}

\begin{abstract}
Between $5 \%$ and $10 \%$ of all breast cancer is hereditary, with patients having a strong family history of the disease. The remaining $90-95 \%$ of cases are classed as sporadic. Within the inherited group, $80-90 \%$ of cases are the result of germline mutations affecting two recently identified genes: BRCA1 and BRCA2. Since the sequencing of these genes, considerable research on the genetics of the mutation carriers has been performed, with less attention having been focused on the BRCA1 and BRCA2 proteins themselves. The structure and function of the protein products thus continues to hold mystery and might be the key to the full understanding of this complex disease.

(F Clin Pathol: Mol Pathol 1998;51:237-247)
\end{abstract}

This review outlines the important structural features of BRCA1 and BRCA2, and their functional role during development and in adult life. For clarity, within each section we have dealt with BRCA1 and BRCA2 separately, despite this leading to some repetition of information. Terminology, annotation, and structural features of BRCA1 and BRCA2 are outlined in tables 1 and 2 .

University

Department of

Surgery, Glasgow

Royal Infirmary, 10

Alexandra Parade,

Glasgow G31 2ER, UK

J A Duncan

J R Reeves

T G Cooke

Correspondence to:

Dr Duncan

email:

cs34c@clinmed.gla.ac.uk

Accepted for publication

9 June 1998

Table 2 Features of mouse and human BRCA1 and BRCA2 genes and proteins

\begin{tabular}{lllll}
\hline & No. of exons & Chromosome & $\begin{array}{l}\text { No. of amino } \\
\text { acids }\end{array}$ & References \\
\hline Mouse Brca1 & NK & 11 & 1812 & 1 \\
Mouse Brca2 & NK & 5 & 3328 & 2,3 \\
Human BRCA1 & 22 & 17 & 1863 & 4 \\
Human BRCA2 & 27 & 13 & 3418 & 5,6 \\
\hline
\end{tabular}

NK, not known.
- This suggests rapid evolutionary change.

- Thus, conserved areas must be expected to have an important function.

BRCA1

BRCA1 (located on chromosome 17q21) encodes a protein composed of 1863 amino acid residues. Similarity of this protein to any other known protein is minimal; however, study of the protein's structure and comparison to its murine counterpart has helped to highlight some regions that are likely to have functional importance. Overall homology between human BRCA1 and its murine counterpart is only $58 \%,{ }^{7}$ a low similarity, suggesting rapid evolution of this gene and protein. Highly conserved regions comprise: a ring finger (RING) domain at the N-terminal region, ${ }^{4}$ an acidic region at the $\mathrm{C}$-terminal region, ${ }^{4}{ }^{1}$ and two putative nuclear localisation signals. ${ }^{89}$ Within the C-terminal region conserved region, a twice repeated motif, now designated the BRCA1 C-terminal (BRCT) domain, shows weak similarity to the mammalian p53 binding protein $53 \mathrm{BP} 1,{ }^{10-12}$ and to the yeast Rad9 protein. ${ }^{11}{ }^{13-15}$ Both of these proteins are involved in DNA repair, implying a functional role for BRCA1 in this area. Most tumorigenic BRCA1 lesions described in hereditary breast cancer families have mutations or deletions in one or both BRCT domains, suggesting that they have a key role in BRCA1 mediated tumour suppression. ${ }^{16} \mathrm{~A}$ centrally placed motif has shown similarity to the granin consensus sequence. ${ }^{17}$ However, the biological relevance of this has been disputed because it is not highly conserved in the mouse. ${ }^{18}$ The same group have described a similar area at the C-terminal region of BRCA2. ${ }^{17}$

Controversy has surrounded the true size and subcellular localisation of BRCA1, with at least some of this being attributable to the existence of splice variants, a number of which have now been isolated. BRCA1 $\Delta 672-4095$ (lacking all exon 11) and BRCA1- $\Delta 11 \mathrm{~b}$ (amino acids 263-1364 deleted, the majority of exon 11 lacking) are both found to localise to the cytoplasm on immunostaining. ${ }^{819}$ Because both nuclear localisation signals identified so far lie within exon 11 it is perhaps not surprising that these splice variants, lacking exon 11, mislocalise to the cytoplasm. Unfortunately, one of these studies ${ }^{8}$ used the C-20 antibody, 
which has since been shown to crossreact with epidermal growth factor receptor and so, although confirming our expectations, the results must still be treated with some caution. Two further alternatively spliced variants, designated BRCA1a and BRCA1b, are both likely to be tyrosine phosphoproteins. Localising to both the cytoplasm and nucleus, and interacting with a number of transcriptional and phosphorylating factors, they might function as negative regulators of the cell cycle. ${ }^{20}$ Interestingly, on immunoblotting analysis, BRCA1$\Delta 11 \mathrm{~b}$ was found to be present in significant quantities in the nuclear fractions, ${ }^{19}$ a result similar to that seen with BRCA1a and BRCA $1 b .^{20}$ The BRCA1 protein splice variants have also been shown to accumulate in the cytoplasm in the presence of serum, but in the nucleus in the absence of serum, suggesting that external stimuli might regulate the subcellular localisation of BRCA1 and its splice variants. Whether the changes in localisation constitute one method of regulation of BRCA1 function remains to be seen.

BRCA2

BRCA2 (located on chromosome 13q12-q13) produces a protein product of 3418 amino acids. A low level of homology is seen between BRCA2 and other proteins, just as with BRCA 1 , with only $59 \%$ homology with mouse Brca 2. ${ }^{2}$ Most of the homologous regions show only weak conservation. An eight times repeated motif is present in the region encoded by exon 11 . Each repeat is variably conserved, suggesting that the core sequence was duplicated eight times during evolution, but that many of the repeats are now redundant. ${ }^{21}$ Within exon 3 lies a region with weak similarity to the transcription factor c-jun, ${ }^{22}$ suggesting a possible role for BRCA2 in the regulation of transcription. A further small area of mouse Brca2 with 95\% homology with human BRCA2 was shown to be able to bind to Rad51,23 implicating BRCA2 in the DNA repair process. And finally, a motif with similarity to the granin consensus sequence ${ }^{17}$ has also been described within the C-terminal region of BRCA2.

To date, no splice variants have been described for BRCA2, with all the recognised mutations causing truncation of the protein product. $^{24}$

\section{Tissue distribution and subcellular localisation \\ KEY POINTS}

- BCRA1 and BCRA2 are temporally and spatially coexpressed in some tissues.

- Differential regulation by ovarian hormones of BCRA1 and BCRA2 occurs.

- Subcellular distribution remains controversial.

- Caution must be observed in interpreting antibody work until antibody specificity is absolutely confirmed.

BRCA1

General opinion on the tissue distribution of Brcal mRNA in adult mouse models agrees
Table 3 Tissue distribution of adult mouse Brca1 mRNA

\begin{tabular}{lll}
\hline & $\begin{array}{l}\text { Adult mouse } \\
\text { Brca1 } \\
m R N A^{\star}\end{array}$ & $\begin{array}{l}\text { Adult mouse } \\
\text { Brca2 } \\
m R N A^{\star *}\end{array}$ \\
\hline Brain & $+/-$ & $+/-$ \\
Heart & - & - \\
Kidney & $+/-$ & - \\
Liver & - & $+/-$ \\
Lung & $+/-$ & - \\
Lymph nodes & $+++/-+$ & $+/-$ \\
Mammary gland (virgin) & $++/-+$ & $+/-\dagger$ \\
Mammary gland (puberty) & ++ & ++ \\
Mammary gland (pregnancy) & +++ & +++ \\
Ovaries & $+++/++$ & ++ \\
Skin & $+/-$ & $\mathrm{NK}$ \\
Spleen & $+++/++$ & $++/-\dagger$ \\
Thymus & $+++/++$ & ++ \\
Testis & $+++/++$ & +++ \\
\hline
\end{tabular}

$+/-$, Barely detectable or no expression; + , very low expression; ++ , moderate expression; +++, high expression; NK, not known.

${ }^{\star}$ References 7, 25, and 26.

$\star \star$ References 2 and 25 .

†Disagreement within literature.

that the highest levels are found in testis, thymus, spleen, ovaries, and the mammary gland during pregnancy (table 3), lower levels being found in the mammary gland during puberty. ${ }^{72-27}$ All of these tissues contain proliferating cellular compartments undergoing differentiation and it has been postulated that Brcal functions as a regulator of differentiation. Because parity is known to confer protection against breast malignancy and Brcal is raised in pregnancy, it might be that Brcal irreversibly alters cells, preventing their reentry into the proliferative cycle and so reducing their opportunity for malignant change. ${ }^{7}$

The subcellular distribution of BRCA1 has been and remains controversial. Complicated by the lack of specificity of the currently available antibodies, ${ }^{28}{ }^{29}$ the problems of working with preserved archival tissue and the presence of various splice variants with alternative functions and localisations are full of pitfalls.

BRCA1 has been claimed to be: (1) exclusively a nuclear protein $^{30}$; (2) a nuclear protein in normal cells but an aberrantly localised cytoplasmic protein in breast and ovarian tumour cells $\mathrm{s}^{31}$; (3) a granin motif containing protein with function as a secreted growth inhibitor $^{17}{ }^{32}$; and (4) most recently, a cytoplasmic protein found in tube-like structures that invaginate the nucleus. ${ }^{33}$ Because the function of BRCA1 is likely to depend on its intracellular localisation, this area is of paramount importance. Experimental observations of two separate mouse polyclonal antibodies raised specifically against separate regions encoded by exon 11 of BRCA1 suggested that BRCA1 was located within the nucleus of normal cells, but excluded to the cytoplasm in sporadic breast and ovarian cancer, and in certain breast and ovarian cell lines. ${ }^{31}$ Contradictory evidence soon came to light with the description of BRCA1 as an exclusively nuclear protein. ${ }^{30}$ In this case, several antibodies were used, both polyclonal and monoclonal, and in all human cell lines, and breast and ovarian cancer cell lines studied, a nuclear dot pattern of staining was seen. However, this staining pattern could become non-nuclear by altering the fixation conditions used in the immunostaining 
Table 4 Intracellular proteins interacting with BRCA1 and BRCA2

\begin{tabular}{|c|c|c|c|}
\hline \multirow[b]{2}{*}{ Protein } & \multicolumn{2}{|l|}{ Putative site of interaction } & \multirow[b]{2}{*}{ Function } \\
\hline & $B R C A 1$ & $B R C A 2$ & \\
\hline Rad51 & Within exon 11 & C-terminal region & DNA repair agent \\
\hline BARD1 & RING motif and C-terminal region & Interaction not described & Unknown \\
\hline p53 & C-terminal region & Unknown & $\begin{array}{l}\text { Maintaining genome integrity } \\
\text { Cell cycle checkpoint regulator } \\
\text { Promoter of apoptosis }\end{array}$ \\
\hline $\mathrm{p} 21^{\text {Waf1/Cip1 }}$ & C-terminal region & Unknown & Cell cycle inhibitor \\
\hline
\end{tabular}

process, ${ }^{30}$ thus suggesting that the variations in subcellular localisation being seen could simply be caused by fixational artefacts. This does not, however, explain the initial findings of nuclear localisation in normal cells but cytoplasmic localisation in tumour cells, given that the fixation conditions were identical in the two settings. ${ }^{31}$

The granin consensus sequence is not well conserved between species, which implies that it does not have an important functional role. Also, it is noteworthy that the main antibody used in this work, C-20, has since been shown to crossreact with the epidermal growth factor receptor. ${ }^{28}{ }^{29}$ Finally, and most recently, BRCA1 has been suggested to be perinuclear in distribution, residing in tubule-like invaginations into the cell nucleus. Again, this distribution was dependent on the method of fixation, ${ }^{33}$ and so currently must be viewed with some scepticism until further confirmatory evidence is available.

In all of these studies, the main concerns are that the specificity of the antibodies used and the fixation techniques are uncertain. Within the controlled setting of cell lines, the antibodies appear to label a protein consistent with BRCA1. It would be foolish to assume that within the complex intracellular world of tertiary structures and associated interacting molecules the same reaction would not be altered significantly, leading to the confusing staining patterns. To confirm without doubt that it is indeed BRCA1 that is being labelled would require purification and sequencing of the labelled protein, for comparison with the known sequence of BRCA1.

BRCA2

Analysis of Brca 2 mRNA concentrations in adult mouse tissues reveals a very similar pattern to that of Brca1. ${ }^{25}$ Brca2 mRNA concentrations, although significantly upregulated during mammary gland development were still only half those reached by Brca1 mRNA. Conversely, Brca 2 mRNA in the testis during the first 4 weeks of life is markedly upregulated compared with Brcal mRNA. Taken together, these results suggest differential regulation of expression of Brca1 and Brca 2 mRNA by sex hormones.

Despite not being investigated as extensively as BRCA1, BRCA2 has already been suggested to be a nuclear protein. ${ }^{34}$ No nuclear localisation signals have been identified to date.

\section{Interacting proteins}

KEY POINTS

- Both BRCA1 and BRCA2 are associated with a number of intracellular proteins (table 4).

- Most of these proteins function as cell cycle checkpoint regulators or DNA repair agents.

- Both BRCA1 and BRCA2 might be involved in a regulatory cascade involving these proteins.

\section{BRCA1}

Reported to localise to discrete, nuclear foci (dots) during S phase, ${ }^{30}{ }^{35}{ }^{36}$ BRCA1 is associated with at least two other proteins, $\operatorname{Rad} 51$ and BARD1, within these foci. Human Rad51, a homologue of bacterial RecA, is a nuclear protein that appears to bind, either directly or indirectly to BRCA 1 , being characterised by nuclear dot-like staining appearing in $\mathrm{S}$ phase. ${ }^{36} 37$ BARD1 contains an $\mathrm{N}$-terminal RING motif, and a C-terminal sequence with significant homology to the BRCT domains of BRCA $1 .{ }^{12}{ }^{16}$ Both these proteins complex with BRCA1 in vivo, ${ }^{16}{ }^{36} 38$ although significant cell to cell variation in complexing was present with Rad51, suggesting that this interaction is transient in nature, even within the $S$ phase cell. ${ }^{36}$ BARD1 interacts directly with BRCA1 in vivo, with this interaction requiring the presence of the RING motif and at least some of the C-terminal region. ${ }^{16}$ Missense mutations of BRCA1 disrupt this interaction, suggesting that the formation of BRCA1/BARD1 heterodimers is likely to be a critical event in BRCA1 mediated tumour suppression. ${ }^{39}$

Synthesised at comparable concentrations throughout the cell cycle, BARD1 polypeptides are apparently distributed diffusely throughout the nucleus during G1 phase. All, or at least a substantial quantity, of these polypeptides must be recruited into the BRCA1 nuclear dots as cells progress into $\mathrm{S}$ phase. Whether this relocation occurs independent of BRCA1 or whether the prior formation of BRCA1/ BARD1 heterodimers is required is not yet clear. $^{39}$ However, it might be significant that BRCA1 has been noted to undergo hyperphosphorylation at this stage of the cell cycle. ${ }^{35}$

Rad51 also localises to nuclear foci in the $S$ phase and must be recruited by an as yet unrecognised system to these sites. A putative binding site has been described within exon $11,{ }^{36}$ in a sequence known to be subject to at least one naturally occurring loss of function missense mutation.

As already described, within the C-terminal region of BRCA1 lies an area with significant homology to the human 53BP1 protein. p53 is well known as a cell cycle checkpoint regulator and promotor of apoptosis. It would be feasible that this area functions as a p53 binding site, ${ }^{12}$ 
implying a direct interaction with BRCA1 and further functional possibilities.

The protein $\mathrm{p} 21^{\mathrm{WAF} 1 / \mathrm{CIP} 1}$ is a universal cell cycle inhibitor that binds specifically to cyclin -CDK (cyclin dependent kinase) complexes and proliferating cell nuclear antigen, thereby serving as a potent growth inhibitor and effector of cell cycle checkpoints. ${ }^{40}$ Via direct interaction with its C-terminal region, ${ }^{41}$ it has been hypothesised that BRCA1 might transcriptionally activate $\mathrm{p} 21^{\mathrm{WAF} 1 / \mathrm{CIP} 1}$ expression and thus negatively regulate cell cycle progression. A number of elegant experiments have confirmed that lack of either $\mathrm{p} 21^{\mathrm{WAF} 1 / \mathrm{CIP} 1}$ or BRCA1 leads to loss of the cell cycle inhibitory effect. ${ }^{42}$ Lack or mutation of specific parts of the BRCA1 C-terminal region led to the inability to activate $\mathrm{p} 21^{\text {WAF1/CIP1 }}{ }^{42}$ These cells then transfected with functional BRCA1 showed a subsequent increase in $\mathrm{p} 21^{\mathrm{WAF} 1 / \mathrm{CIP} 1}$, suggesting that the activation of $\mathrm{p} 21^{\mathrm{WAF} 1 / \mathrm{CIP} 1}$ requires functional BRCA1. This is in direct contradiction to the observation that cells from BRCA1 null mouse embryos have increased concentrations of $\mathrm{p} 21^{\mathrm{WAF} 1 / \mathrm{CIP} 1}$ mRNA. ${ }^{43}$ BRCA1 might, however, have different functional roles in embryonic development, as will be discussed in a later section.

BRCA2

Similarly, Brca 2 has been shown to interact with $\operatorname{Rad} 51, \mathrm{p} 53$, and $\mathrm{p} 21^{\text {Waf1/CIP1 }}$. The region of Brca2 that interacts with Rad51 is contained within the C-terminal region and shows 95\% homology with human BRCA2. Deficiency of either Rad51 or Brca 2 in embryonic mice leads to extreme sensitivity to irradiation, suggesting a symbiotic relation between these two proteins in protecting the genome from damage. ${ }^{23} \mathrm{Simi}-$ lar to Brca 1 null murine embryos, $\mathrm{p} 21^{\text {Waf1/CIP1 }}$ is upregulated in Brca2 null murine embryos. In association with this, an upregulation of p53 is seen. Both $\mathrm{p} 21^{\text {Wafl/CIP1 }}$ and $\mathrm{p} 53$ are known to cause cell cycle arrest, suggesting that the loss of Brca2 leads to defective DNA repair, resulting in the accumulation of spontaneous DNA damage and activation of p53 and p $21^{\text {Waf1/CIP1 }}{ }^{44}$ Alternatively, p53 and p21 might interact directly with Brca2. Mutation might disrupt this interaction, allowing upregulation of activity of $\mathrm{p} 21^{\text {Wafl/CIP1 }}$ and $\mathrm{p} 53$. There is little described in the literature regarding the relation between $\mathrm{p} 21^{\text {Waf1/CIP1 }}$ and Brca 2 in adult life. It will be interesting to see whether, similar to Brca1, functional, active Brca 2 is required in adult life to activate $\mathrm{p} 21^{\text {Wafl/CIP1 }}$.

\section{Phosphorylation/dephosphorylation} KEY POINTS

- Phosphorylation/dephosphorylation occurs in a cell cycle associated manner.

- Phosphorylation/dephosphorylation might regulate BRCA1 activity.

- Hyperphosphorylation is not the signal for localisation to nuclear foci.

BRCA1

BRCA1 undergoes hyperphosphorylation in the late G1 and S phases of the cell cycle, coinciding with its reported localisation to discrete nuclear dots, and is then transiently dephosphorylated immediately after $M$ phase, in the very early part of the G1 phase. ${ }^{35}$ The fact that BRCA1 is phosphorylated in parallel with its synthesis suggests that the phosphorylated form is the active one. However, this has been challenged by Zhang et al, who claim that hyperphosphorylated BRCA1 is found in quiescent cells and cells arrested at the G2/M checkpoint with, conversely, reduced BRCA1 phosphorylation being seen at times of unrestricted cell cycle progression, proliferation, and transformation. ${ }^{45}$ Despite this controversy, the phosphorylation and dephosphorylation of BRCA1 is likely to be a significant regulator of BRCA1 activity as a cell cycle checkpoint controller at the G1/S phase and/or G2/M phase transition points.

The protein kinase(s) and protein phosphatase(s) could therefore perform the important task of regulating BRCA1 activity. Already suggested for this role have been CDK2-cyclin $\mathrm{D}$ or CDK2-cyclin A complexes, ${ }^{35}$ both of which have been shown to be capable of phosphorylating BRCA1 in vitro. Given the recognised association of hyperphosphorylated BRCA1 and its localisation to nuclear dots, it is interesting to note that exposure of cells to DNA damaging agents causes promotion of hyperphosphorylation yet leads to the elimination of the punctate nuclear staining pattern normally seen for BRCA1. This suggests that hyperphosphorylation itself is not the localising signal for congregation to nuclear foci. ${ }^{46}$

BRCA2

As yet, nothing is described in the literature regarding phosphorylation and dephosphorylation of BRCA2.

\section{Cell cycle associations}

KEY POINTS

- BRCA1 and BRCA2 expression parallels the cell cycle phases.

- The time of maximal BRCA1 and BRCA2 expression coincides with maximum cellular growth and differentiation.

BRCA1

Fluxes in BRCA1 (and BRCA2) expression are associated with cell cycle phases in both normal mammary epithelial cells, and breast and ovarian cancer cell lines, ${ }^{35}{ }^{47-49}$ with expression being induced maximally just before cell entry into $S$ phase, at the time when maximal growth and differentiation is occurring. ${ }^{750}$ From the information outlined above, it is clear that the degree of hyperphosphorylation correlates closely with changes in BRCA1 protein concentrations, alteration in subcellular localisation, and changes in BRCA1 mRNA concentrations. $^{3551}$ This supports the hypothesis that BRCA1 functions as a cell cycle regulator at the G1/S phase transition and/or at the G2/M phase transition. Aprelikova et al claim, however, that no change in overall BRCA1 protein level is seen when MCF10A cells are growth arrested or stimulated to proliferate. ${ }^{52}$ Indeed, it might be the case that the actual protein concentration remains unchanged but 
the physical state is altered by the addition or removal of phosphate groups. Protein expression, subcellular distribution, and function might all be regulated by similar if not the same interactions.

BRCA2

BRCA2 mRNA expression has been shown to be regulated with the cell cycle and associated with proliferation in both normal and tumour derived breast epithelial cells. ${ }^{50}{ }^{53}$ Similar to that seen with BRCA1, cells arrested in G0 or early G1 contained little BRCA2 mRNA. Once released into the proliferating phase however, BRCA2 mRNA concentrations rise, reaching a maximum in late $\mathrm{G} 1$ and $S$ phases. ${ }^{50} 5354$ In association with this, the BRCA2 protein has also been shown to be induced in late G1/early $S$ phase, before DNA synthesis, implying that this rise is not simply secondary to the increase in proliferation. ${ }^{34}$ This coincides with the time of maximum cellular growth and differentiation..$^{50}$

\section{Hormonal regulation}

KEY POINTS

- Sex hormones, directly or indirectly, regulate BRCA1 and BRCA2 expression.

- Differential expression of BRCA1 and BRCA2 occurs secondary to sex hormone stimuli.

- Phenotypic differences associated with BRCA1 and BRCA2 germline mutations might be secondary to differential regulation by these hormones.

BRCA1

That ovarian hormones might regulate BRCA1 expression was suggested by the observation in mice that Brcal mRNA expression was substantially upregulated during pregnancy. Expression of BRCA1 (and BRCA2) has been shown to be induced by $17-\beta$ oestradiol in oestrogen receptor positive breast cancer cell lines. ${ }^{77}$ In the mammary glands of ovariectomised mice, Brcal mRNA is significantly lower than in age matched intact animals, but can be restored to normal values by the administration of oestradiol and progesterone in combination..$^{25} 27$

Recent observations suggest that the induction of expression of BRCA1 and BRCA2 by oestrogen occurs secondary to promotion of DNA synthesis and not, as was originally thought, as a direct effect. This conclusion is supported by various pieces of evidence, namely: (1) the oestrogen response of BRCA1 is delayed when compared with the $\mathrm{pS} 2$ gene, which is induced directly by hormone occupied oestrogen receptors, being more comparable with cyclin A expression ${ }^{55}$; (2) the response of both BRCA1 and BRCA2 is blocked by cyclohexamide, a protein synthesis inhibitor, whereas pS2 expression is not, indicating that ongoing protein synthesis is required for oestrogen mediated induction of BRCA1 transcription; (3) it is impossible to uncouple increased expression of BRCA1 from an increase in the percentage of cells undergoing DNA synthesis; and (4) a screen for oestrogen responsive elements in the BRCA1 gene yielded two possible candidates. ${ }^{56}$ Because it is thought unlikely that oestrogen would act to stimulate the gene directly, the oestrogen receptor was cotransfected with oestrogen into MCF-7 and SK-BR-3 cells. However, the candidate sequences within the BRCA1 gene were both totally non-responsive. Both elements were highly responsive in the human hepatoma line treated under the same conditions, ${ }^{57}$ underlining the differing tissue specificity of these elements. ${ }^{56}$

An interesting finding in mice is that Brcal expression in the breast is markedly greater in females than in males, whereas Brca 2 expression levels are very similar. We know that BRCA1 is associated with an increased risk of breast cancer in females only, while BRCA2 is associated with an increased risk in both males and females. It is possible that the gender specific differences in breast cancer risk associated with germline mutations in BRCA1 and BRCA2 might simply reflect the differential regulation of these genes by sex hormones. ${ }^{25}$

BRCA2

BRCA2 (like BRCA1) is induced by $17-\beta$ oestradiol, secondary to DNA synthesis, this effect being blocked by antioestrogens and cyclohexamide, as above. ${ }^{47}$ As outlined above, Brca2 mRNA expression is induced during pregnancy in parallel with Brcal mRNA. Interestingly, Brca2 mRNA is markedly upregulated in the testis in the first 4 weeks of life, whereas Brcal mRNA values remain essentially unchanged. ${ }^{25}$ The significance of these findings has yet to be elucidated.

\section{Pathology}

KEY POINTS

- Specific phenotypic features are associated with both BRCA1 and BRCA2 mutation carriers.

- The site of the mutation within BRCA1 is associated with different phenotypes.

- The size of the BRCA1 protein fragment relates to age of onset and severity of disease. Despite poor prognostic indicators, BRCA1 (and possibly BRCA2) mutation carriers tend to have better overall survival than their sporadic counterparts.

BRCA1

BRCA1 germline mutation carriers and patients with sporadic breast cancers present with differing phenotypic features (table 5). In addition to those features outlined below, there is also a suggestion that breast tumours from BRCA1 germline mutation carriers are significantly more often DNA non-diploid, proliferative, and oestrogen receptor, progesterone receptor, and c-erbB2 negative than their non-mutant BRCA1 counterparts. ${ }^{586162}$ One small study contradicts these findings, suggesting that BRCA1 mutation carriers are more likely to be progesterone receptor positive; in addition, this study found no definite relation with oestrogen receptors. ${ }^{63}$ Thus, it remains to be seen whether a clear relation exists with BRCA1 in this area. An excess of ductal 
Table 5 Phenotypic differences between BRCA1 germline mutation carriers and sporadic breast cancers

\begin{tabular}{|c|c|c|c|c|c|c|}
\hline \multirow[b]{2}{*}{ Phenotypic feature } & \multicolumn{2}{|l|}{ Study $1^{58}$} & \multicolumn{2}{|l|}{ Study $2^{59}$} & \multicolumn{2}{|l|}{ Study $3^{60}$} \\
\hline & $\begin{array}{l}\text { BRCA1 (\%) } \\
n=40\end{array}$ & $\begin{array}{l}{ }^{\star} \text { Control }(\%) \\
n=100\end{array}$ & $\begin{array}{l}\text { BRCA1 (\%) } \\
n=75\end{array}$ & $\begin{array}{l}{ }^{*} \text { Control }(\%) \\
n=75\end{array}$ & $\begin{array}{l}B R C A 1(\%) \\
n=118\end{array}$ & $\begin{array}{l}\text { tControl }(\%) \\
n=547\end{array}$ \\
\hline \multicolumn{7}{|l|}{ Histology } \\
\hline Ductal & 95 & 77 & 66.7 & 60.0 & 74 & 74 \\
\hline Lobular & 0 & 17 & 6.7 & 18.7 & 3 & 10 \\
\hline Lobular features & NA & NA & 9.3 & 26.7 & NA & NA \\
\hline Tubular & 0 & 2 & NA & NA & 2 & 5 \\
\hline TLG & NA & NA & 6.7 & 32.0 & NA & NA \\
\hline Medullary & 0 & 2 & 13.3 & 4.0 & NA & NA \\
\hline Atypical medullary & NA & NA & 13.3 & 2.7 & NA & NA \\
\hline All medullary & NA & NA & NA & NA & 13 & 2 \\
\hline \multicolumn{7}{|l|}{ Histological grade } \\
\hline I & 3 & 23 & NA & NA & 9 & 24 \\
\hline II & 5 & 33 & NA & NA & 25 & 40 \\
\hline III & 93 & 44 & 62 & 29.5 & 66 & 36 \\
\hline \multicolumn{7}{|l|}{ Nuclear grade } \\
\hline I & 0 & 10 & NA & NA & 4 & 10 \\
\hline II & 8 & 42 & NA & NA & 23 & 38 \\
\hline III & 93 & 48 & 44 & 34.1 & 73 & 52 \\
\hline \multicolumn{7}{|l|}{ Mitotic rate } \\
\hline 1 & 3 & 23 & NA & NA & 26 & 53 \\
\hline 2 & 20 & 32 & NA & NA & 15 & 17 \\
\hline 3 & 78 & 45 & 56 & 15.9 & 59 & 30 \\
\hline Lymphocyte infiltration rate & & & NA & $\mathrm{NA}$ & NA & NA \\
\hline 0 & 3 & 0 & & & & \\
\hline I & 15 & 32 & & & & \\
\hline II & 26 & 46 & & & & \\
\hline III & 56 & 22 & & & & \\
\hline DNA diploidy & NA & NA & 13.6 & 40.9 & NA & NA \\
\hline
\end{tabular}

NA, not available; TLG, tubular-lobular group.

${ }^{\star}$ Control group, 100 stage II breast cancers with the same age distribution as the hereditary breast cancers.

${ }^{\star \star}$ Control group consists of "other" inherited breast cancers, 75 cases comprising 17 with BRCA2 mutations and 58 without identified BRCA1 or BRCA2 mutations or linkage or ovarian cancer occurrences.

†Control group, randomly selected historical controls from apparently sporadic female breast cancer cases from histopathology archives of department of histopathology, Royal Marsden Hospital, Sutton, Surrey.

carcinomas has been described ${ }^{586465}$ and, furthermore, Marcus et al reported an excess of tumours with medullary, atypical medullary, and no special type with medullary features within his group of ductal carcinomas. ${ }^{64}$

Paradoxically, despite all the adverse prognostic indicators, BRCA1 associated patients are predisposed to lower recurrence rates and better overall survival than other patients with hereditary breast cancer. ${ }^{59}{ }^{64}$ This might be explained by the over-representation of medullary and atypical medullary carcinomas within the BRCA1 tumour group because, despite its threatening pathological appearance, pure medullary carcinoma has a significantly better survival rate than other forms of breast cancer. ${ }^{59}$ This is also the case for BRCA1 associated ovarian carcinomas, which have higher mitotic rates than their sporadic counterparts, and yet have better case survival rates. ${ }^{66}$ Interestingly, BRCA1 associated tumours also appear to have a lesser degree of in situ carcinoma associated with them, suggesting that they might represent a different form of carcinogenesis, with a reduced precancerous stage and a more rapidly progressing invasive cancer. This would or should lead to a lower risk of local recurrence in these patients following adequate surgical intervention. ${ }^{67}$

The site of the gene mutation also seems to be important. Highly proliferative tumours are associated mainly with mutations close to either the $5^{\prime}$ or $3^{\prime}$ end of BRCA $1 .^{68}$ The closer the mutation lies to the 5 ' terminal region of the gene (the N-terminal region of the protein) the higher the likelihood of ovarian (as opposed to breast) carcinoma, suggesting the presence of a domain that protects against ovarian cancer within the N-terminal region. ${ }^{69}$ It seems that the change in ovarian cancer risk between the two ends of the gene occurs at a sharp transition point located in the area of the boundary of exons 12 and 13, rather than as a smooth gradation of risk through the entire gene. ${ }^{69}$ This suggests that the postulated "protective" domain might be situated in this area. If this domain is left unaffected by a mutation, then the risk of ovarian cancer remains low; however, if disrupted, the risk of ovarian cancer is increased substantially.

The length of the protein product of the mutated BRCA1 gene correlates with age of onset and severity of disease. ${ }^{70}$ The longer the protein fragment synthesised (or alternatively, the shorter the segment lost from the protein), the earlier the tumour will be manifest and the greater the disease severity. ${ }^{70}$ For example, a mutation at base pair 5385 (5385insC) leads to a stop of translation at codon 1829 and thus loss of the terminal 34 amino acids. ${ }^{4}$ Patients with this mutation present at a very young age (third and early fourth decade) and commonly have bilateral breast cancers. ${ }^{4} 70$ Alternatively, a mutation in exon 2 (187delAG), causing deletion of two base pairs and thus termination of the protein product at codon 39 (mid-RING finger motif) is associated with unilateral tumours with onset in the fifth decade. ${ }^{70}$ Because most mutations result in BRCA1 protein truncation, most cases $(87 \%)$ will lack the C-terminal region. ${ }^{16}{ }^{70}$ This loss has been said to be the vital step in the development of breast cancer. What are the domains within the C-terminal region that are essential for normal development? A p53 binding domain has already been muted to be present within the 
Table 6 BRCA2 phenotypic features ${ }^{60}$

\begin{tabular}{lll}
\hline & $\begin{array}{l}\text { BRCA2 (\%) } \\
\text { Phenotypic feature }\end{array}$ & $\begin{array}{l}{ }^{\star} \text { Control (\%) } \\
n=547\end{array}$ \\
\hline $\begin{array}{l}\text { Histology } \\
\text { Ductal }\end{array}$ & 76 & 74 \\
Lobular & 10 & 10 \\
$\quad$ Tubular & 0 & 5 \\
All medullary & 3 & 2 \\
Histological grade & & \\
I & 11 & 24 \\
II & 48 & 40 \\
III & 41 & 36 \\
Nuclear grade & & \\
I & 5 & 10 \\
II & 40 & 38 \\
III & 55 & 52 \\
Tubule formation & & \\
1 & 1 & 8 \\
2 & 12 & 66 \\
3 & 87 & 53 \\
Mitotic rate & & 17 \\
1 & 47 & 30 \\
2 & 26 & \\
3 & 27 & \\
\hline
\end{tabular}

${ }^{\star}$ Control group, randomly selected historical controls from apparently sporadic female breast cancer cases from histopathology archives of department of histopathology, Royal Marsden Hospital, Sutton, Surrey. ${ }^{60}$

C-terminal region. ${ }^{12}$ It might be that a short protein chain with no p53 binding site present is less harmful to the cell than a larger molecule hindered by an incomplete p53 binding domain, because the incorrect interaction with p53 might result in early disregulation of cellular metabolism. ${ }^{70}$

BRCA2

Cancers arising in BRCA2 mutation carriers are likely to be of the tubular-lobular group, ${ }^{596164}$ with accompanying lobular carcinoma in situ (table 6). This contradicts the observation that the tumours of BRCA2 mutation carriers are of higher grade than controls because of a lower rate of tubule formation. ${ }^{60}{ }^{63}$ Apart from the generally small numbers, much of the data within these studies regarding BRCA2 mutation carriers continues to be mixed up in a heterogenous group labelled non-BRCA1 related hereditary breast carcinoma, a relic from the days before the sequencing of the BRCA2 gene. Obviously, this group might contain hereditary breast cancers caused by as yet undiscovered genes and so might not be phenotypically representative of tumours caused by germline mutations in BRCA2.$^{64}$ Thus, any conclusions drawn from this heterogeneous group must be viewed with some caution.

\section{Role in embryogenesis}

KEY POINTS

- The dynamic expression of Brca 1 and Brca2 during embryogenesis is almost identical.

- Regulation of Brca1 and Brca2 during development might be by the same pathway.

- Overlapping functions of Brca 1 and Brca2 is possible, although unlikely, during development and unlikely in adult life, given that the increased cancer risk still occcurs even if one of these genes is normal.

BRCA1

During murine embryogenesis, both Brcal and Brca2 mRNA values vary in their temporal and spatial degree of expression (table 7). Analysis
Table 7 Temporal and spatial localisation of Brca1 and Brca2 expression during foetal development ${ }^{2}$

\begin{tabular}{lll}
\hline Tissue & $\begin{array}{l}\text { Gestational } \\
\text { day 13.5 }\end{array}$ & $\begin{array}{l}\text { Gestational } \\
\text { day 18.5 }\end{array}$ \\
\hline Liver & + & + \\
Midgut & + & - \\
Ventricular layer of brain & + & + \\
Germinal neuroblastic epithelium of & & \\
developing eye & + & - \\
Lung & - & + \\
Bowel (non-specific) & - & + \\
Salivary glands & - & + \\
Thymus & - & + \\
Tooth bud & - & + \\
Brown adipose tissue & - & + \\
Skin & - & + \\
Olfactory epithelium & - & + \\
\hline
\end{tabular}

+ , Expressed at high level; -, expressed at low level or not at all.

of Brcal mRNA during this time has demonstrated peak expression of mRNA at day 13.5 of gestation, with lower but detectable values at days 6.5 and $18.5 .^{25}$

Disruption of Brcal during embryogenesis has shown that it plays a vital role at this stage. Nullizygous mouse embryos become developmentally retarded and disorganised, and die early in development. A Brcal mutant mouse model has been produced by deleting exons 5 and 6 of the Brcal coding region $\left(\mathrm{Brca}^{5-6}\right)$, leading to the introduction of termination codons in all three reading frames and the removal of the zinc finger domain. Heterozygous $\left(\mathrm{Brca}^{+/}\right)$mice are normal and fertile, and lack tumours by 11 months. Homozygous Brca $^{5-6}$ mutant mice die before day 7.5 of embryogenesis. Before day 7.5, embyos show two differing degrees of severity of phenotypic abnormality. Those less severely affected are under half the size of their wild-type counterparts, and show no clear boundary between the embryonic and the extra-embryonic regions. The more severely affected group contains embryos with no morphological organisation. The reason for these differences is unknown but might relate to presence or loss of other genes such as p53. Resorption of mutant embryos begins on day $7.5,{ }^{43}$ corresponding with the initial rise of Brcal mRNA values to their peak at day 13.5. In contrast, Brcal mutant mice obtained by deletion of exon $11^{71}$ demonstrate survival until midgestation, with death occurring in utero between days 10 and 13 of development. Thus, the mutants described above have different phenotypes, and although both are lethal, the Brca $1^{5-6}$ mutant appears to be more severely affected at an earlier stage. This suggests a vital role for exons 5 and 6 in very early embryonic survival, with exon 11 being important for continuing development and survival at a slightly later stage. The impact of Brca1 and Brca2 null mutations and the associated phenotypic abnormalities are much less severe in a p53 null setting. ${ }^{10}$ Because inhibition of cell cycle progression and promotion of apoptosis are included among the diverse functions of $\mathrm{p} 53$, the lethality of Brca 1 and Brca 2 null mutants could be attributed to their inability to downregulate p53 activity, leading to growth arrest and apoptotic death. Lack of p53, however, means that proliferation and differentiation can continue unchecked, 
and although disorganised and including many uncorrected errors, the embryo will survive longer before eventual death. Indirect evidence for the upregulation of $\mathrm{p} 53$ activity exists, given that the expression of p21 (an important target gene of p53) has been shown to be increased and the expression of mdm-2 (a gene encoding a negative regulator of $\mathrm{p} 53$ ) has been shown to be reduced in the Brcal null setting. ${ }^{43}$ If BRCA1 functions as a growth regulator and cell cycle regulator, it could be expected that loss of function would lead to aberrant overgrowth of tissues, with the presence of multiple mutations, as we see in tumours. Because of its regulatory functions, BRCA1 has a role in the maintenance of genome integrity. Loss of its function will precipitate genome errors, leading to activation of checkpoint genome guardian functions, cell cycle arrest, and upregulation of DNA repair mechanisms. This will lead to protection of the overall tissue integrity or, if repair is impossible, sacrifice of the cells by apoptosis. The argument then ensues that tumorigenesis and uncontrolled cell proliferation would occur only if a second event, such as loss of genome guardian function (that is, loss of $\mathrm{p} 53$ function) occurs, suggesting that BRCA1 might be only part of a cascade of damage leading ultimately to aberrant cellular behaviour. ${ }^{36}$ If, however, p53 and $\mathrm{p} 21^{\text {Wafl/Cip1 }}$ are dependant on BRCA 1 for activation to their functional states, it is possible to see how the solitary event of loss of BRCA1 function would lead directly to tumorigenesis by disruption of the whole complex regulatory network.

Although embryonic lethality occurs in all the Brca 1 mouse mutants, a 32 year old patient has been described with inherited homozygosity for a BRCA1 mutation that would result in a truncated protein of only 900 amino acids. ${ }^{72}$ If this patient is genuinely homozygous, this suggests that BRCA1 is not essential for human embryogenesis. Whether this difference would then reflect BRCA1 functional divergence in humans and mice remains open to debate. Within the Ashkenazi Jewish population there is a population frequency of $\sim 1 \%$ for the 185 delAG mutation within BRCA1. Thus, it would be expected that a number of homozygotes would also be present. However, none has ever been identified, lending support to the theory that homozygous BRCA1 mutants are embryonic lethals.

Expression of p21 $1^{\text {Waf1//ip1 }}$, a potent cell cycle inhibitor, is elevated in Brcal null mouse embryos. ${ }^{43}$ This directly contradicts the previous observations that BRCA1 is required for the transcriptional activation of $\mathrm{p} 21^{\text {Wafl/Cip } 1} .^{41}$ However, the function of BRCA1 during development and embryogenesis might differ, with BRCA1 suppressing $\mathrm{p} 21^{\text {Wafl/Cip1 }}$ expression during development to allow cell growth. ${ }^{43}$ Loss of BRCA1 therefore allows unchecked expression of $\mathrm{p} 21^{\text {Wafl/Cip } 1}$. The level of expression and the effect on the cell cycle of $\mathrm{p} 21^{\text {Wafl/Cip1 }}$ protein in the Brcal null mouse embryo has not yet been determined. Equally, the mechanism of increased $\mathrm{p} 21^{\text {Waf1/Cip1 }}$ expression remains unclear. ${ }^{43}$
BRCA1 protein and BRCA1 mRNA have both been described at significantly raised concentrations in the nuclei of human spermatocytes. ${ }^{26}{ }^{36}$ Two possible modes of action have been suggested for BRCA1; first, that it is an upstream regulator of the meiotic crossover process and, alternatively, that it functions as a DNA repair and cell cycle checkpoint agent. In yeast, it is well recognised that Rad51 plays a vital role in double stranded break repair, meiotic recombination, ${ }^{73}$ and normal replication. ${ }^{74}{ }^{75}$ Because BRCA1 and Rad51 are known to interact, it is reasonable to assume that this might have an effect on cell cycle progression, DNA replication, and even maintenance of genomic integrity.

BRCA2

Similar work has been performed with the Brca2 mutant mouse model (Brca $2^{\mathrm{Brdm} 1}$ ), produced by disruption of exon 11 , and leading to formation of a mutant Brca2 protein lacking amino acids 626-1437. Once again, heterozygotes are healthy and fertile and have no sign of tumorigenesis by 8 months of age. Homozygotes do not survive embryogenesis, being apparently phenotypically normal at day 6.5, but showing abnormalities by day 7.5 , with the main abnormality appearing to be the lack of formation of mesoderm, and the absence of amnion, allantois, and chorion. ${ }^{23}$ Again, this corresponds with the first gestational day of increased expression of Brca2.

\section{Role in adult life \\ KEY POINTS}

- Both BRCA1 and BRCA2 are likely to have a role within the transcriptional activation cascade.

- Other potential functional activities require further elucidation.

- The role of BRCA1 and BRCA2 in the aetiology of sporadic breast tumours remains to be clarified.

BRCA1

Transcriptional regulator, cell cycle checkpoint effector, apoptotic regulator, genome guardian, DNA repair agent - all have been postulated as functions of the BRCA1 protein.

Within BRCA1, we have already noted the RING finger, found in many transcription factors and believed to mediate sequence specific DNA binding ${ }^{69}$; a putative p53 binding site within the C-terminal region ${ }^{12}$; and the similarity of the BRCT domains to nuclear proteins with cell cycle checkpoint and DNA repair functions. ${ }^{11} 12$

When fused to the GAL4 DNA binding domain, the C-terminal region (exons 16-24) can activate transcription, both in yeast and mammalian cells. Specific mutations occurring within the C-terminal region (table 8) greatly impair this transcriptional function. ${ }^{41} 76$

In the regulation of apoptosis, when transfected into mouse fibroblasts and human breast cancer cell lines, BRCA1 appears to cause altered morphology, which in the face of further stresses (serum deprivation or calcium ionophore treatment), leads to programmed 
Table 8 Transcriptional activation by BRCA1C terminus $^{4175}$

\begin{tabular}{|c|c|}
\hline Construct (amino acids) & $\begin{array}{l}\text { Relative } \\
\text { activity }\end{array}$ \\
\hline \multicolumn{2}{|l|}{ Wild type } \\
\hline BRCA1 (1560-1863) & 1.0 \\
\hline BRCA1 (1560-1823) & 0.0 \\
\hline BRCA1 (1560-1803) & 0.0 \\
\hline BRCA1 (1560-1778) & 0.0 \\
\hline BRCA1 (1760-1863) & 0.6 \\
\hline BRCA1 (1779-1863) & 0.0 \\
\hline BRCA1 (1760-1803) & 0.0 \\
\hline \multicolumn{2}{|l|}{ Mutants } \\
\hline BRCA1 (1560-1863) Ala-1708 $\rightarrow \mathrm{Glu}^{\star}$ & 0.0 \\
\hline 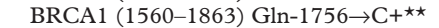 & 0.0 \\
\hline BRCA1 (1560-1863) Met-1775 $\rightarrow$ Arg^ & 0.0 \\
\hline BRCA1 (1560-1863) Tyr-1853 $\rightarrow$ stop $^{\star \star}$ & 0.0 \\
\hline BRCA1 (1560-1863) Pro-1749 $\rightarrow$ Arg $\dagger$ & 0.0 \\
\hline
\end{tabular}

Each BRCA1 coding region was fused to the DNA binding domain of GAL4 to create a GAL4-BRCA1 fusion protein.

${ }^{\star}$ Clinically recognised substitution mutation reported in patients with breast cancer.

$\star \star$ Insertions leading to truncated BRCA1 protein products. †Clinically recognised substitution mutation reported in a patient with ovarian cancer.

cell death, while untransfected cells subjected to the same environment show lower levels of apoptosis. ${ }^{77}$ The potential interaction of BRCA1 with p53 via a binding site in the C-terminal region has already been discussed. Thus, BRCA1 might act as a regulator of $\mathrm{p} 53$ function and so indirectly affect the apoptotic potential of cells. Because disruption of apoptotic regulation is central to malignancy, lack or inappropriate expression of functional BRCA1 might be central to this process in breast and ovarian malignancies (including sporadic tumours).

As outlined above, BRCA1 is expressed in a cell cycle dependent manner, with hyperphosphorylation occurring at specific transitional phases within the cell cycle, although exactly which, is still under debate. ${ }^{35}{ }^{45}$ Despite this, it is fair to say that the association of phosphorylation and dephosphorylation with the cell cycle checkpoints would support the suggestion that BRCA1 acts as a cell cycle regulator at the G1/S phase and/or G2/M phase transition points.

Given our understanding of tumour suppressor gene function, BRCA1 is likely to function as part of a signal cascade with cell cycle progression upregulating certain signals, leading to increased expression and hyperphosphorylation (or dephosphorylation) of BRCA1, which then acts at the cell cycle checkpoint(s) regulating entry into $\mathrm{S}$ and/or $\mathrm{M}$ phases and so inhibits cell cycle progression. Loss of this negative feedback loop, as occurs in tumours, would lead to unhindered progression through the cell cycle, with no correction of mutational errors.

It has been suggested that BRCA1 exhibits properties of a granin, being localised in secretory granules, released after stimulation by an activator of cAMP, post-translationally modified, and induced by oestradiol. If this is the case, then BRCA1 functions by a novel mechanism for a tumour suppressor gene product. ${ }^{17}$ The same group have demonstrated that overexpression of BRCA1 inhibits the growth of breast and ovarian cancer cells. This growth inhibition is specific for certain cell types, unlike previously described tumour suppres- sors, such as p53 and the retinoblastoma gene product $(\mathrm{Rb})$, which interact with ubiquitous cell cycle mechanisms. The suggestion is that BRCA1 might inhibit growth of only those cells containing either a regulated secretory pathway or an appropriate receptor. ${ }^{32}$

Whether BRCA1 has a role in the aetiology of sporadic breast tumours or not continues to be hotly debated. Despite extensive searching, somatic mutations have been described in only a handful of cases of sporadic breast or ovarian cancers. ${ }^{78-81}$ Loss of heterozygosity, reflecting gene inactivation, has been reported for both the BRCA1 and the BRCA2 loci in sporadic tumours. ${ }^{82-84}$ However, because other tumour suppressor genes are known to occupy sites adjacent to these loci, it might be that the elevated loss of heterozygosity data simply reflects allele loss affecting these neighbouring genes. ${ }^{63}$

BRCA2

BRCA2, like BRCA1, has been suggested to have a transcriptional function. Exon 3 of BRCA2 (which lies within the region highly conserved between mouse and human) shows sequence homology to the activation domain of c-jun, and has the potential to activate transcription in yeast. Lying on either side of exon 3 are regions that negatively regulate its expression, masking the activating potential of BRCA $2 .{ }^{22}$

The cell cycle kinetics of BRCA2, although less fully explored than those of BRCA1, appear to be very similar. BRCA2 $\mathrm{mRNA}$ is maximal in late $\mathrm{G} 1 / \mathrm{S}$ phase, its expression once again being independent of bulk DNA synthesis. ${ }^{53}$ It would not be unreasonable to postulate a similar cell cycle checkpoint function for BRCA2 as for BRCA1. However, simply because the patterns of expression are similar does not give us a good enough reason to assume overlapping functions for BRCA1 and BRCA2.

No irrefutable evidence exists to associate BRCA2 mutations with sporadic breast cancers. As already commented on, however, loss of heterozygosity indicating allele loss or inactivation has been identified at the BRCA2 loci. ${ }^{82}{ }^{85}$ However, this observation must be viewed with caution because it is well known that the Rb1 gene loci (among others) are situated in this area, and the loss of heterozygosity might simply reflect the presence of these other tumour suppressor genes.

\section{Conclusions}

Germline mutations in BRCA1 or BRCA2 are causative in the majority of inherited breast and ovarian cancers. No somatic mutations have yet been described in sporadic breast cancers and only one or two have been identified in sporadic ovarian cancers. However, in nonfamilial breast and ovarian cancer it is possible that an abnormality occurs within the actual BRCA1 or BRCA2 gene product, affecting its function and leading to the same deleterious effect as a germline mutation.

Within the next few years the subcellular localisation and function of BRCA1 and BRCA2 should be clarified and, with this 
information, it is hoped that the roles of BRCA1 and BRCA2 in health and disease will become a great deal clearer.

1 Abel KJ, Xu JZ, Yin GY, et al. Brca1-localization, sequence-analysis and identification of evolutionarily consequence-analysis and identification of evolutionarily

2 Sharan SK, Bradley A. Murine Brca2: sequence, map position, and expression pattern. Genomics 1997;40:234-41.

3 Connor F, Smith A, Wooster R, et al. Cloning, chromosomal mapping and expression pattern of the mouse Brca2 gene. Hum Mol Genet 1997;6:291-300.

4 Miki Y, Swensen J, Shattuckeidens D, et al. A strong candidate for the breast and ovarian-cancer susceptibility gene BRCA1. Science 1994;266:66-71.

5 Wooster R, Neuhausen SL, Mangion J, et al. Localization of a breast-cancer susceptibility gene, BRCA2, to chromosome 13q12-13. Science 1994;265:2088-90.

6 Tavtigian SV, Simard J, Rommens J, et al. The complete BRCA2 gene and mutations in chromosome 13q-linked BRCA2 gene and mutations in ch
kindreds. Nat Genet 1996;12:333-7.

7 Lane TF, Deng CX, Elson A, et al. Expression of Brca1 is associated with terminal differentiation of ectodermally and mesoderm

8 Thakur S, Zhang HB, Peng Y, et al. Localization of BRCA1 and a splice variant identifies the nuclear localization signal. Mol Cell Biol 1997;17:444-52.

9 Chen CF, Li S, Chen YM, et al. The nuclear localization sequences of the BRCA1 protein interact with the importin-alpha subunit of the nuclear transport signal receptor. F Biol Chem 1996;271:32863-8.

10 Ludwig T, Chapman DL, Papaioannou VE, et al. Targeted mutations of breast cancer susceptibility gene homologs in mice: lethal phenotypes of Brca1, Brca2, Brca1/Brca2, Brca1/p53, and Brca2/p53 nullizygous embryos. Genes Dev 1997;11:1226-41.

11 Callebaut I, Mornon JP. From BRCA1 to RAP1: a widespread BRCT module closely associated with DNA $7 ; 400: 25-30$

12 Jensen $\mathrm{Ra}$, Thompson Me, Jetton Tl, et al. BRCA1 protein products - antibody specificity ... functional motifs ... and secreted tumor suppressors - reply. Nat Genet 1996;13: 269-72.

13 Siede W, Friedberg AS, Dianova I, et al. Characterization of $\mathrm{G}_{1}$ checkpoint control in the yeast saccharomycescerevisiae following exposure to DNA-damaging agents. Genetics 1994;138:271-81

14 Weinert TA, Hartwell LH. The Rad9 gene controls the cellcycle response to DNA damage in saccharomycescerevisiae. Science 1988;241:317-22.

15 Koonin EV, Altschul SF, Bork P. Functional motifs. Nat Genet 1996;13:266-8.

16 Wu LJC, Wang ZW, Tsan JT, et al. Identification of a RING protein that can interact in vivo with the BRCA1 gene product. Nat Genet 1996;14:430-40.

17 Jensen RA, Thompson ME, Jetton TL, et al. BRCA1 is secreted and exhibits properties of a granin. Nat Genet 1996;12:303-8.

18 Bradley A, Sharan SK. Brcal protein products-secreted tumor suppressors. Nat Genet 1996;13:268-9.

19 Wilson CA, Payton MN, Elliott GS, et al. Differential subcellular localization, expression and biological toxicity of BRCA1 and the splice variant BRCA1- $\Delta 11 \mathrm{~b}$. Oncogene 1997;14:1-16.

20 Wang HC, Shao NS, Ding QM, et al. BRCA1 proteins are transported to the nucleus in the absence of serum and transported to the nucleus in the absence of serum and
splice variants BRCA1a, BRCA1b are tyrosine phosphoproteins that associate with E2F, cyclins and cyclin proteins that associate with E2F, cyclins
dependent kinases. Oncogene 1997;15:143-57.

21 Bignell G, Micklem G, Stratton MR, et al. The BRC repeats are conserved in mammalian BRCA2 proteins. Hum Mo Genet 1997;6:53-8

22 Milner J, Ponder B, Hughes Davies L, et al. Transcriptional activation functions in BRCA2. Nature 1997;386:772-3.

23 Sharan SK, Morimatsu M, Albrecht U, et al. Embryonic lethality and radiation hypersensitivity mediated by Rad51 in mice lacking Brca2. Nature 1997;386:804-10.

24 Mazoyer S, Dunning AM, Serova O, et al. A polymorphic stop codon in BRCA2. Nat Genet 1996;14:253-4.

25 Rajan JV, Marquis ST, Gardner HP, et al. Developmental expression of Brca2 colocalizes with Brca1 and is expression of Brca 2 colocalizes with Brcal and is tissues. Dev Biol 1997;184:385-401.

26 Zabludoff SD, Wright WW, Harshman K, et al. BRCA1 messenger-RNA is expressed highly during meiosis and spermiogenesis but not during mitosis of male germ-cells. Oncogene 1996;13:649-53.

27 Marquis ST, Rajan JV, Wynshawboris A, et al. The developmental pattern of Brca1 expression implies a role in differentiation of the breast and other tissues. Nat Genet 1995;11:17-26.

28 Thomas JE, Smith M, Rubinfeld B, et al. Subcellularlocalization and analysis of apparent $180-\mathrm{kda}$ and $220-\mathrm{kda}$ proteins of the breast-cancer susceptibility gene, BRCA1. $\mathcal{F}$ Biol Chem 1996;271:28630-5.

29 BernardGallon DJ, Crespin NC, Maurizis JC, et al. Cross-reaction between antibodies raised against the last 20 C-terminal amino acids of BRCA 1 (C-20) and human EGF and EGF-R in MCF 10a human mammary epithelial cell line. Int $\mathcal{F}$ Cancer 1997;71:123-6.
30 Scully R, Ganesan S, Brown M, et al. Location of BRCA1 in human breast and ovarian-cancer cells. Science 1996;272: 123-5.

31 Chen Y, Chen CF, Riley DJ, et al. Aberrant subcellular localization of BRCA1 in breast cancer. Science 1995;270: 789-91.

32 Holt JT, Thompson ME, Szabo C, et al. Growth-retardation and tumor-inhibition by BRCA1. Nat Genet 1996;12:298302.

33 Coene E, Van Oostveldt P, Willems K, et al. BRCA1 is localized in cytoplasmic tube-like invaginations in the nucleus. Nat Genet 1997;16:122-4.

34 Bertwistle D, Swift S, Marston NJ, et al. Nuclear location and cell cycle regulation of the BRCA2 protein. Cancer Res 1997;57:5485-8.

35 Chen Y, Farmer AA, Chen CF, et al. BRCA1 is a $220-\mathrm{kDa}$ nuclear phosphoprotein that is expressed and phosphorylated in a cell cycle-dependent manner. Cancer Res 1996; 56:3168-72.

36 Scully R, Chen JJ, Plug A, et al. Association of BRCA1 with Rad51 in mitotic and meiotic cells. Cell 1997;88:265-75.

37 Tashiro S, Kotomura N, Shinohara A, et al. S-phase specific formation of the human Rad51 protein nuclear foci in lymphocytes. Oncogene 1996;12:2165-70.

38 Scully R, Chen JJ, Ochs RL, et al. Dynamic changes of BRCA1 subnuclear location and phosphorylation state are initiated by DNA damage. Cell 1997;90:425-35.

39 Jin Y, Xu XL, Yang MCW, et al. Cell cycle-dependent colocalization of BARD1 and BRCA1 proteins in discrete
nuclear domains. Proc Natl Acad Sci USA 1997;94:1207580 .

40 Sherr CJ, Roberts JM. Inhibitors of mammalian $G_{1}$ cyclin-dependent kinases. Genes Dev 1995;9:1149-63.

41 Chapman MS, Verma IM. Transcriptional activation by BRCA1. Nature 1996;382:678-9.

42 Somasundaram K, Zhang HB, Zeng YX, et al. Arrest of the cell cycle by the tumour-suppressor BRCA1 requires the CDK-inhibitor p21(waf1/cip1). Nature 1997;389:187-90.

43 Hakem R, delaPompa JL, Sirard C, et al. The tumorsuppressor gene Brcal is required for embryonic cellular proliferation in the mouse. Cell 1996;85:1009-23.

44 Connor F, Bertwistle D, Mee PJ, et al. Tumorigenesis and a DNA repair defect in mice with a truncating Brca2 mutation. Nat Genet 1997;17:423-30.

45 Zhang HT, Zhang X, Zhao HZ, et al. Relationship of p215(BRCA1) to tyrosine kinase signaling pathways and the cell cycle in normal and transformed cells. Oncogene 1997;14:2863-9.

46 Thomas JE, Smith M, Tonkinson JL, et al. Induction of phosphorylation on BRCA1 during the cell cycle and after DNA damage. Cell Growth Differ 1997;8:801-9.

47 Spillman MA, Bowcock AM. BRCA1 and BRCA2 messenger-RNA levels are coordinately elevated in human breast-cancer cells in response to estrogen. Oncogene 1996;
13:1639-45.

48 Gudas JM, Li T, Nguyen H, et al. Cell-cycle regulation of BRCA1 messenger-RNA in human breast epithelial-cells. Cell Growth Differ 1996;7:717-23.

49 Vaughn JP, Davis PL, Jarboe MD, et al. BRCA1 expression is induced before DNA-synthesis in both normal and tumor-derived breast cells. Cell Growth Differ 1996;7:711-

50 Rajan JV, Wang $M$, Marquis ST, et al. BRCA2 is coordinately regulated with BRCA1 during proliferation and differentiation in mammary epithelial-cells. Proc Natl Acad Sci USA 1996;93:13078-83.

51 Ruffner H, Verma IM. BRCA1 is a cell cycle-regulated nuclear phosphoprotein. Proc Natl Acad Sci USA 1997;94: 7138-43.

52 Aprelikova O, Kuthiala A, Bessho M, et al. BRCA1 protein level is not affected by peptide growth-factors in MCF10a cell-line. Oncogene 1996;13:2487-91.

53 Vaughn JP, Cirisano FD, Huper G, et al. Cell-cycle control of BRCA2. Cancer Res 1996;56:4590-4.

54 Wang SC, Lin SH, Su LK, et al. Changes in BRCA2 expression during progression of the cell cycle. Biochem Biophys Res Commun 1997;234:247-51.

55 Gudas JM, Nguyen H, Li T, et al. Hormone-dependent regulation of BRCA1 in human breast-cancer cells. Cancer Res 1995;55:4561-5.

56 Marks JR, Huper G, Vaughn JP, et al. BRCA1 expression is not directly responsive to estrogen. Oncogene 1997;14:11521.

57 Norris J, Fan DJ, Aleman C, et al. Identification of a new subclass of Alu DNA repeats which can function as estrogen receptor-dependent transcriptional enhancers. $\mathcal{F}$ Biol Chem 1995;270:22777-82.

58 Johannsson OT, Idvall I, Anderson C, et al. Tumour biological features of BRCA1-induced breast and ovarian cancer. Eur f Cancer 1997;33:362-71.

59 Marcus JN, Page DL, Watson P, et al. BRCA1 and BRCA2 hereditary breast carcinoma phenotypes. Cancer 1997;80: 543-56.

60 Lakhani SR, Easton DF, Stratton MR, et al. Pathology of familial breast cancer: differences between breast cancers in carriers of BRCA1 or BRCA2 mutations and sporadic cases. Lancet 1997;349:1505-10.

61 Marcus JN, Watson P, Page DL, et al. BRCA2 and BRCA1 breast cancer phenotypes. Lab Invest 1997;76:110

62 Karp SE, Tonin PN, Begin LR, et al. Influence of BRCA1 mutations on nuclear grade and estrogen receptor status of breast carcinoma in Ashkenazi Jewish women. Cancer 1997;80:435-41. 
63 Beckmann MW, Picard F, An HX, et al. Clinical impact of detection of loss of heterozygosity of BRCA1 and BRCA2
markers in sporadic breast-cancer. Br f Cancer 1996;73: markers

64 Marcus JN, Watson P, Page DL, et al. Hereditary breast-cancer-pathobiology, prognosis, and BRCA1 and BRCA2 gene linkage. Cancer 1996;77:697-709.

65 Eisinger F, Stoppalyonnet D, Longy M, et al. Germ-line mutation at BRCA1 affects the histoprognostic grade in hereditary breast-cancer. Cancer Res 1996;56:471-4.

66 Rubin SC, Benjamin I, Behbakht K, et al. Clinical and pathological features of ovarian-cancer in women with
germ-line mutations of BRCA1. N Engl f Med 1996;335: 1413-6.

67 Jacquemier J, Eisinger F, Guinebretier JM, et al. Intraductal component and BRCA1-associated breast-cancer. Lancet 1996;348:1098

68 Sobol A, Stoppalyonnet D, BressacDePaillerets B, et al. Truncation at conserved terminal regions of BRCA1 protein is associated with highly proliferating hereditary protein is associated with highly proliferating

69 Stratton MR, Wooster R. Hereditary predisposition to breast-cancer. Curr Opin Genet Dev 1996;6:93-7.

70 Grade K, Hoffken K, Kath R, et al. BRCA1 mutations and phenotype. 7 Cancer Res Clin Oncol 1997;123:69-70.

71 Gowen LC, Johnson BL, Latour AM, et al. Brca1 deficiency results in early embryonic lethality characterized by neuroepithelial abnormalities. Nat Genet 1996;12:191-4.

72 Boyd M, Harris F, Mcfarlane R, et al. A human BRCA1 gene knockout. Nature 1995;375:541-2.

73 Shinohara A, Ogawa H, Ogawa T. Rad51 protein involved in repair and recombination in saccharomyces-cerevisiae is a recA-like protein. Cell 1992;69:457-70.

74 Lim DS, Hasty P. A mutation in mouse Rad51 results in an early embryonic lethal that is suppressed by a mutation in p53. Mol Cell Biol 1996;16:7133-43.
75 Tsuzuki T, Fujii Y, Sakumi K, et al. Targeted disruption of the Rad51 gene leads to lethality in embryonic mice. Proc Natl Acad Sci USA 1996;93:6236-40.

76 Monteiro ANA, August A, Hanafusa H. Evidence for a transcriptional activation function of BRCA1 C-terminal region. Proc Natl Acad Sci USA 1996;93:13595-9.

77 Shao NS, Chai YL, Shyam E, et al. Induction of apoptosis by the tumor-suppressor protein BRCA1. Oncogene 1996; 13:1-7.

78 Futreal PA, Liu QY, Shattuckeidens D, et al. BRCA1 mutations in primary breast and ovarian carcinomas. Science 1994;266:120-2.

79 Merajver SD, Pham TM, Caduff RF, et al. Somatic mutations in the BRCA1 gene in sporadic ovarian-tumors. Nat Genet 1995;9:439-43.

80 Hosking L, Trowsdale J, Nicolai $\mathrm{H}$, et al. A somatic BRCA1 mutation in an ovarian tumor. Nat Genet 1995;9:343-4.

81 Takahashi H, Behbakht K, Mcgovern PE, et al. Mutation analysis of the BRCA1 gene in ovarian cancers. Cancer Res 1995;55:2998-3002.

82 Cletonjansen AM, Collins N, Lakhani SR, et al. Loss of heterozygosity in sporadic breast-tumors at the BRCA2 locus on chromosome 13q12-q13. Br f Cancer 1995;72:1241-4.

83 Cropp CS, Nevanlinna HA, Pyrhonen S, et al. Evidence for involvement of BRCA1 in sporadic breast carcinomas. Cancer Res 1994;54:2548-51.

84 Futreal PA, Soderkvist P, Marks JR, et al. Detection of frequent allelic loss on proximal chromosome-17q in sporadic breast-carcinoma using microsatellite length polymorphisms. Cancer Res 1992;52:2624-7.

85 Hamann U, Herbold C, Costa S, et al. Allelic imbalance on chromosome $13 \mathrm{q}$-evidence for the involvement of BRCA2 and RB1 in sporadic breast-cancer. Cancer Res 1996;56:1988-90. 